\title{
Front Matter: Volume 10269
}

, "Front Matter: Volume 10269," Proc. SPIE 10269, Optical Technologies for Aerospace Sensing: A Critical Review, 1026901 (16 November 1992); doi: $10.1117 / 12.2284881$

SDIE Event: Applications in Optical Science and Engineering, 1992, Boston, MA, SPIE. United States 


\section{Contents}

vii Conference Committee

ix Preface

\section{SENSOR TECHNOLOGIES}

3 Recent developments in infrared detectors and focal plane arrays

R. E. Sampson, Environmental Research Institute of Michigan

19 Optical components and coatings for aerospace sensing

A. F. Slomba, United Technologies Optical Systems

45 Lasers for airborne applications

S. Guch, Jr., D. P. Stanley, Litton Systems, Inc.

64 Imaging IR sensors: future directions for test and evaluation G. D. Boreman, CREOL/Univ. of Central Florida

\section{SENSOR SIGNAL PROCESSING}

Optical processing and computing

R. A. Athale, George Mason Univ.

94 Optical data storage and retrieval: research directions for the '90s

S. E. Esener, J. E. Ford, S. Hunter, Univ. of California/San Diego

131 Optical pattern recognition

D. P. Casasent, Carnegie Mellon Univ.

\section{AEROSPACE SENSORS}

153 Star sensors for autonomous attitude control and navigation R. W. H. van Bezooijen, Lockheed Palo Alto Research Lab.

181 Laser remote sensing in atmospheric sciences, aviation safety, aeronautical research, and experiments from space platforms and high-flying aircraft

F. Allario, P. Brockman, R. R. Antcliff, W. B. Grant, NASA Langley Research Ctr.

234 Photonics for aerospace sensors

J. M. Pellegrino, E. Adler, A. N. Filipov, L. J. Harrison, J. van der Gracht,

D. J. Smith, T. Tayag, E. A. Viveiros, Army Research Lab.

Optical Technologies for Aerospace Sensing: A Critical Review, edited by James E. Pearson, Proc. of SPIE Vol. 10269 (Vol. CR47), 1026901 - ( ) (1992) 2017 SPIE · CCC code: 0277-786X/17/\$18 · doi: 10.1117/12.2284881 


\section{SENSING APPLICATIONS}

273 Optical instruments for remote sensing from space M. P. Chrisp, Jet Propulsion Lab.

285 MODIS: a global imaging spectroradiometer for the Earth Observing System

W. L. Barnes, V. V. Salomonson, NASA Goddard Space Flight Ctr.

308 Laser radar systems and applications

M. J. Halmos, J. H. S. Wang, Hughes Aircraft Co. 


\title{
Conference Committee
}

\author{
Conference Chair \\ James E. Pearson, United Technologies Research Center
}

\section{Session Chairs}

Session 1-Sensor Technologies

James E. Pearson, United Technologies Research Center

Session 2-Sensor Signal Processing

Brian M. Hendrickson, Rome Laboratory

Session 3-Aerospace Sensors

Edward R. Washwell, Lockheed Missiles \& Space Company, Inc.

Session 4-Sensing Applications

James B. Breckinridge, Jet Propulsion Laboratory

Session 5-Applications of Fiber Optic Sensors

William B. Spillman, Jr. University of Vermont 


\section{Preface}

Optical technologies for sensing in aerospace applications have matured to the point where they are in widespread use, rapidly replacing many types of mechanical, electronic, and microwave-based sensors. Optical sensing techniques are now common in such diverse applications as navigation and guidance; image and data capture, storage, and retrieval; velocimetry; remote species detection; object identification and ranging; earth observation; and high-speed imaging. Photon-based sensing techniques have always been the technology of choice when the application required high information collection rate, remote location of the sensor, high precision, immunity to electromagnetic interference, or some combination of these features. Passive imaging-ground-based, airborne, or space-based-is perhaps the most obvious optical sensor application.

Early aerospace optical sensing was limited, however, by the resolution and speed of recording and transmission media, and by the long times required to process the large amount of data. In addition, the power, brightness, and spectral purity of optical sources limited the precision and remote sensing distance in many applications. The advantages of optical sensing thus also were the source of many of their limitations. Low application volume often kept costs high, further limiting application.

The advent of high-speed signal processing, megapixel detector arrays, and the laser has removed or greatly reduced many of the limitations of optical sensing. In addition, low cost, small size, low power consumption, and high reliability are features of photon-based sensors now available to the sensor designer and user.

This critical review was designed to survey the state of the art in optical sensing and sensor-related technologies, and to forecast future directions for the technologies as well as their applications. Selected applications are described to illustrate current use and technical challenges. The papers were originally presented as part of the Boston OE/Technology symposium in a two-day conference, 16-17 November 1992.

Session 1, Sensor Technologies, deals with the components of sensors: detectors (Robert Sampson), optics (Albert Slomba), and lasers (Steve 
Guch and Doug Stanley). Infrared scene projection is described by Glenn Boreman to illustrate the current state of the art and future developments in selected components.

Session 2, Sensor Signal Processing, addresses the use of optical technologies for signal processing, which offers the prospect of even higher processing speeds than that of microelectronic computers. Ravindra Athale discusses a unified view of different approaches to optical information processing and computing. The paper by Sadik Esener, Joseph Ford, and Susan Hunter reviews the exploitation of threedimensional optical storage to meet the needs for high-performance information storage and retrieval. David Casasent discusses optical pattern recognition using optical correlator techniques.

Session 3, Aerospace Sensors, looks at selected applications of optical sensors in aerospace applications. The paper by Roelof W. H. van Bezooijen describes how optical star sensors have improved the accuracy of autonomous attitude control and navigation. Laser remote sensing for a variety of purposes is reviewed in a paper by Frank Allario, Philip Brockman, R. R. Antcliff, and William Grant. John Pellegrino et al. address fiber optic links and optical signal processing, particularly their use in synthetic aperture radar (SAR) and automatic target recognition (ATR) applications.

Session 4, Sensing Applications, focuses on remote sensing and laser radar applications. Michael Chrisp reviews the design of passive remote sensing instruments for use on space platforms. William Barnes and Vincent Salomonson describe the MODIS instrument, one of the several optical sensors planned for NASA's Earth Observing System(EOS). Laser radar (LADAR) techniques, technologies, and applications are reviewed in the paper by Maurice Halmos and John Wang.

James E. Pearson 